\title{
Relationship between sources of counseling self-efficacy and counseling self-efficacy among Malaysian school counselors
}

\author{
Pei Boon Ooi ${ }^{\mathrm{a}, \mathrm{b}, *}$, Wan Marzuki Bin Wan Jaafar ${ }^{\mathrm{b}}$, Maznah Binti Baba ${ }^{\mathrm{b}}$ \\ a Sunway University, Malaysia \\ b Universiti Putra Malaysia, Malaysia
}

\section{A R T I C L E I N F O}

\section{Article history:}

Received 9 June 2015

Received in revised form 11 May 2017

Accepted 23 May 2017

Available online $\mathrm{xxx}$

\section{Keywords:}

Sources of counseling self-efficacy

Mastery experience

Counseling self-efficacy

School counselor

\begin{abstract}
A B S T R A C T
School counselors' role in the formation and transformation of the Malaysian education system is indispensable. This study employs the Social Cognitive Theory to examine the relationship between the sources of counseling self-efficacy and the Malaysian school counselors' counseling self-efficacy. The Sources of Counseling Self-Efficacy questionnaire and the Counseling Self-Estimate Inventory were used on 541 school counselors nationwide, as the respondents. The result reveals mastery experience has the strongest relationship with counseling self-efficacy. Recommendations on how to strengthen self-efficacy are proposed.
\end{abstract}

(c) 2017 Western Social Science Association. Published by Elsevier Inc. All rights reserved.

\section{Introduction}

The role of school counselors has evolved and transformed over the years, in Malaysia and in the Western countries (Wilde, Park \& Lee, 2013). In 1963, the Malaysian Ministry of Education implemented the idea of having guidance teachers in schools but the idea was aborted due to financial limitation and human resources constraint (See \& Ng, 2010). In the year 2000, another milestone was achieved by the counseling profession when it became mandatory for every secondary school in Malaysia to have at least one full-time counselor. The school counselor job is to focus solely on guidance and counseling services without the additional teaching workload. The Parliament of Malaysia enacted the Counselor Act 1998 (Act 580, Commissioner of Law Revision) in the year 1998. This provision boosted the confidence of the community in sourcing for legitimate counseling services.

\footnotetext{
* Corresponding author.

E-mail addresses: peiboonooi@hotmail.com (P.B. Ooi), wanmarzuki@upm.edu.my (W.M.B. Wan Jaafar), mazb@upm.edu.my (M.B. Baba).
}

The self-efficacy concept received considerable attention over the past 30 years and was widely studied since Albert Bandura introduced the term in 1986. From a personal and professional development perspective, the concept of self-efficacy is positively associated with selfregulations (Zimmerman \& Bandura, 1994), self-concept (Bong \& Skaalvik, 2003) and mastery goal orientation to influence academic performance outcomes (Fenollar, Roman \& Cuestas, 2007; Stajkovic \& Sommer, 2000). Self-efficacy belief also predicts the individual's major career decision and career choice and is associated with key motivation variables such as job satisfaction. For instance, a lower level of self-efficacy denotes a lower level of job satisfaction and a higher level of job stress (Klassen \& Chiu, 2010). Career researchers who studied self-efficacy reported that self-efficacy is correlated with job search planning and job search behavior (Fort, Jacquet, \& Leroy, 2011), career indecision among high school students (Argyropoulou, Sidiropoulou-Dimakakou, \& Besevegis, 2007), and career counseling attitude (AlDarmaki, 2012).

Bandura (1997) suggests that individuals constructed their self-efficacy beliefs from four primary sources: enac- 
tive mastery experience, vicarious experience, verbal or social persuasion, and physiological and affective state. Numerous studies focused on the correlation or sources of self-efficacy's outcomes, but relatively few examined the actual sources. There are various measurements constructed to measure the four sources in different domains. However, to the researcher's best knowledge, none of the measurements examined the sources of self-efficacy in the counseling domain.

According to Bandura's Social Cognitive Theory (SCT) (Bandura, 1989, 1990), humans are capable of forming, filtering, and deciding their course of actions via triadic reciprocity within the behavior, cognitive, and other personal factors and environmental events. The behavior is predictable and reciprocally influenced by both cognitive and environment determinants (Sawyer, Peters, \& Willis, 2013). The study by Ooi, Wan Jaafar, and Baba (2016) suggests that counselors registered with the Malaysia Board of Counselor display a higher level of counseling selfefficacy and a higher level of job satisfaction, self-perceived employability, career success, and professional commitment. Thus, it is imperative to study the relationship between the four sources and counseling self-efficacy from the self-belief perspective.

\subsection{Self-efficacy belief}

The most common construct being studied in Social Cognitive Theory studies is self-efficacy beliefs and within the central construct of the beliefs lies the specific and general self-efficacy constructs. The specific self-efficacy construct has been widely used and developed to measure various domains such as job search self-efficacy (Lahuis, 2005) and the Teacher Self-Efficacy (Palmer, 2011). On the other hand, under the general self-efficacy construct, numerous general scales have been developed, such as social self-efficacy (Workplace Social Self-Efficacy (Fan et al., 2013)), occupational self-efficacy (Rigotti, Schyns, \& Mohr, 2008), and youth self-efficacy (Warren \& Salazar, 2014).

Various counseling self-efficacy scales have been developed to measure its different domains. An instrument to measure racial diversity was developed by Sawyer, Peters, and Willis (2013). The Counselor's Self-Efficacy Scale (CSES) aims to measure the beginner master level counseling students' willingness to conduct counseling session and to support clients during a crisis. The scale has 42 items with four subscales: (a) crisis situation (13 items), (b) basic counseling skills (15 items), (c) therapeutic response to crisis and post-crisis ( 8 items), and (d) unconditional positive regard (6 items). The reliability coefficient ranging from .96 to .98 suggested that perceived self-efficacy and preparedness to handle crisis are correlated. Acknowledging the different needs of elementary, middle, and high school counselors' self-efficacy, Can (2010) developed and validated the Elementary School Counselors' Self-Efficacy beliefs (ESCSE) with three main factors, namely counseling, consultation, and coordination. Each factor accounted for $25 \%, 19 \%$ and $17 \%$ of the total variance, respectively. The $21-$ item Scale reported a Cronbach alpha coefficient of .92 and a test-retest of .82 and was deemed valid to measure self- efficacy beliefs of the elementary school counselors. The original 31 items were reduced to 21 items that met the criteria after the principle component analysis and repeated varimax rotation operation.

\subsection{Sources of self-efficacy}

The four sources of information efficacy in which selfefficacy is learned are (1) mastery experience, (2) social persuasion, (3) vicarious learning, and (4) physiological and anxiety state. The mastery experience or the performance accomplishment refers to how people act on their efficacy beliefs and assess the adequacy of their self-appraisal from their achieved performance (Bandura, 1997, p. 81). This is the most influential source of efficacy information (Bandura, 1997). Past success in performing counseling activities will elevate the efficacy appraisal; repeated failures would inflict the efficacy appraisal, especially if this happens in the early stage of counseling and could not be explained by the amount of effort invested or affected by external circumstances. Social persuasion, which encompasses both verbal and non-verbal feedbacks and judgment received from others cultivate one's beliefs in one's ability to perform duties and activities (Britner \& Pajares, 2006). However, social persuasion alone is insufficient to sustain the effect of increasing one's self-efficacy (Bandura, 1986). Social persuasion was found to modestly contribute to the prediction of academic grade and courses of self-efficacy (Usher \& Pajares, 2009). One's beliefs are easily weakened by the negative appraisal or bad comments received.

The third source, vicarious experience, was reported as the strongest predictor of self-efficacy for self-regulated learning (Usher \& Pajares, 2009). Vicarious experience is less influential in the presence of mastery experience (Britner \& Pajares, 2006) but heavily relied on when one has limited experience or knowledge in the tasks or activities that others performed. The physiological and anxiety states, such as anxiety, stress, mood states, and stimulation also provide efficacy information. One depends on information gathered from one's physiological state in forming a judgment on one's abilities and capabilities. Pain, fatigues, stress, tension, and windedness or any perceived negative arousal prevent success and prohibit positive desired outcomes. In a nutshell, one may interpret the internal state differently depending on one past experience in managing similar tasks or activities, the complexity of the tasks, and how others perform such tasks. Some may dwell on internal sensory whilst some may be more externally driven (Bandura, 1997).

\subsection{Counseling self-efficacy}

Counseling self-efficacy (CSE) which stemmed from SCT is defined as “one's beliefs or judgments about her/his capability to effectively counsel clients in the near future (Larson \& Daniels, 1998). It is not about the degree, credential, year of experience one has, or the counseling skills and techniques one possesses; but one's self-beliefs in conducting counseling-related activities, such as individual counseling, group counseling, and development programs. It is important to note that a CSE scale does not measure 
one's counseling performance, but one's self-estimate of his or her future performance.

Counseling self-efficacy could affect counselor performance (Iannelli, 2000) and from the supervisor's perspective (Hanson, 2006) it may also affect the quality and deliverance of effective practice among school mental health clinicians (Schiele, 2013). CSE also could generate an effective assessment and treatment of school children with mental health needs (Schiele, Weist, Youngstrom, Stephan, \& Lever, 2014). A trainee with a higher counseling self-efficacy believes he or she is capable of performing counseling-related tasks as compared to trainees who perceived themselves as having a lower counseling self-efficacy. Wan Jaafar, Mohamed, Bakar, and Ahmad Tamizi (2009) supported the significance and the influencing role of counseling self-efficacy (CSE) on a trainee counselor's performance. However, Sharply and Ridgway (1993) reported there was no relationship between CSE and performance. Meanwhile, Havens (2003) investigated the relationship between mental health counselor's selfefficacy and multicultural counseling competency; and reported a marginal statistical significance between counselor self-efficacy and multicultural competence.

Given the aforementioned studies and mixed findings, this study proposed the following hypotheses:

a) There is a positive relationship between mastery experience and counseling self-efficacy.

b) There is a positive relationship between social persuasion and counseling self-efficacy.

c) There is a positive relationship between vicarious learning and counseling self-efficacy.

d) There is a negative relationship between physiological and affective state and counseling self-efficacy.

\section{Methods}

\subsection{Participants}

Five hundred and forty-one (541) of secondary school counselors in Malaysia took part in this study; 421 (77.8\%) female participants and 120 (22.2\%) male participants. The sample is drawn randomly from the Malaysian Education Management Information System (EMIS). The participant age ranges from 23 to 60 years old $(M=39.34, S D=8.89)$.

\subsection{Measures}

The survey consists of three ( 3 ) sections; the last section is the demographic segment with nine (9) questions. The questionnaire is translated into the Bahasa Malaysia (BM) language (Malaysia official language), which was printed in a smaller font after the English version. The participants were reminded that the English version is the official version whereas the BM version serves as a guideline.

The Sources of Counseling Self-Efficacy Scale adopted from the Mathematics Self-Efficacy Scale (Usher \& Pajares, 2009) is used to measure the participants' self-efficacy. A consent for modification was obtained from the original authors and changes were made to reflect the self-efficacy measure in the counseling context. The word 'mathematics' is substituted with the word "counseling". For examples, "I have always been successful with math" was modified to "I have always been successful with counseling tasks/work" and "My math teachers have told me that I am good at learning math" was modified to "My counseling supervisors have told me that I am good at conducting counseling sessions". Three expert panels with more than 10 years of experience in counseling reviewed the instrument to validate the content. The panels agreed that the changes made to the instrument are sufficient and appropriate for this study.

The Sources of Counseling Self-Efficacy Scale has 25 items and is reported with good internal consistency with the Cronbach's Alpha of .87 for mastery experience, .86 for social persuasion, .93 for vicarious learning, and .92 for the physiological and affective state (Usher \& Pajares, 2009). The value that exceeds .70 is acceptable for research purpose (Nunnally \& Bernstein, 1994). The participants were asked to rate each statement and each item with scales ranging from 1 (definitely false, or Big F) to 6 (definitely true, or Big T).

The Counseling Self-Efficacy Inventory (COSE) is used to measure counseling self-efficacy belief. The inventory consists of 37 items with five subdomains, namely microskills, the counseling process, dealing with difficult client behaviors, cultural competency, and awareness of values (Larson et al., 1992). The 6-point Likert scale ranges from 1 (strongly disagree) to 6 (strongly agree). Nineteen (19) items (item $2,6,7,9,16,18,19,21,22,23,24,26,27,28,31,33$, 35,36 , and 37 ) require reverse-scoring. The Cronbach's alpha coefficients for the COSE total score is $\alpha=.93$ and the five subdomains are .88 for microskills, .87 for processing, .80 for difficult clients, .80 for behaviors, and .78 for cultural competence (Larson et al., 1992). The total score is preferred over the separate subdomain scores. The score ranges from 37 to 222 with a higher total scores represent a higher perception of counseling self-efficacy (Easton, Martin, \& Wilson, 2008).

\subsection{Data analysis}

Data analysis was performed using the Analysis of Moment Structure (AMOS version 22) and SPSS version 16. An adequate fit of the model is achieved when three to four indices meet the cutoff point of .90 (Hair, Black, Babin, \& Anderson, 2010). In this study, the Goodness of Fit Indexes (GFI), Comparative Fit Index (CFI) and Incremental Fix Indexes (IFI) are used as the fit indexes and the cutoff point is set as .90 and above.

\section{Results}

\subsection{Descriptive statistics}

The skewness, kurtosis, and unidimensionality were assessed and no violation was found (Tabachick \& Fidell, 2007). Data distribution is normal. All data are within the range given with skewness ranges from -1.384 to 1.608 and kurtosis ranges from -.713 to 4.254 .

Table 1 shows that the vicarious learning reports has the highest mean ( $M=36.05, S D=3.652)$,follows by 
Table 1

The descriptive data of constructs.

\begin{tabular}{llll}
\hline Variable & Mean & Standard deviation & Maximum \\
\hline Mastery experience & 29.26 & 4.226 & 6 \\
Social persuasion & 32.10 & 2.553 & 36 \\
Vicarious learning & 36.05 & 3.652 & 36 \\
Physiological and affective state & 9.820 & 3.328 & 25 \\
Counseling self-efficacy & 166.23 & 21.52 & 6 \\
\hline
\end{tabular}

Table 2

The correlation estimation among the constructs.

\begin{tabular}{|c|c|c|c|c|c|}
\hline Variables & 1 & 2 & 3 & 4 & 5 \\
\hline Mastery experience & 1 & & & & \\
\hline Social persuasion & $.126^{*}$ & 1 & & & \\
\hline Vicarious learning & $.167^{* *}$ & $.526^{* *}$ & 1 & & \\
\hline Physiological and affective state & $.119^{*}$ & .053 & -.014 & 1 & \\
\hline Counseling self efficacy & $.414^{* *}$ & $.150^{*}$ & $.113^{*}$ & $-.028^{*}$ & 1 \\
\hline
\end{tabular}

${ }^{*} p<.05$.

** $p<.001$

Table 3

Hypothesized paths.

\begin{tabular}{|c|c|c|c|c|c|}
\hline Hypothesized relationship & & Estimate & S.E. & Estimate (Beta) & C.R. \\
\hline Mastery experience & $\rightarrow$ Counseling self-efficacy & .428 & .052 & $.411^{* *}$ & 8.167 \\
\hline Social persuasion & $\rightarrow$ Counseling self-efficacy & .154 & .074 & $.112^{*}$ & 2.072 \\
\hline Vicarious learning & $\rightarrow$ Counseling self-efficacy & -.020 & .066 & -.017 & -.310 \\
\hline Physiological and affective state & $\rightarrow$ Counseling self-efficacy & -.098 & .050 & $-.086^{*}$ & -1.975 \\
\hline
\end{tabular}

* $p<.05$.

$p<.001$.

social persuasion $(\mathrm{M}=32.10, \mathrm{SD}=2.553)$, mastery experience $(M=29.26, S D=4.226)$, and physiological and affective state $(M=9.820, S D=3.328)$.

Table 2 shows the correlations among the constructs. All correlations are in the expected directions and statistically significant among variables. Mastery experience is positively associated with counseling self-efficacy $(p<.001)$. Social persuasion and vicarious learning are positively associated with counseling self-efficacy $(p<.05)$, whereas the physiological and affective state is negatively associated with counseling self-efficacy $(p<.05)$.

\subsection{Measurement model}

Measurement model was performed with the pooled confirmatory factor analysis (CFA). All the factor loadings for the indicators on the latent variables were statistically significant and reported adequate internal consistency among the items measured. As presented in Fig. 1, the Goodness of Fit (GOF), shows that the CFI, IFI, TLI significantly pass its' cutoff value of $.90, \mathrm{x}^{2}(340)=657.352$, $\mathrm{GFI}=.922, \mathrm{CFI}=.964 ; \mathrm{IFI}=.964, \mathrm{NFI}=.928, \mathrm{TLI}=.960$, and RMSEA $=.042$, which fall within the recommended range of .3 and .8 (Hair, Black, Babin, Anderson, \& Tatham, 2006); thus, the data fit the model.

\subsection{Structural model}

The hypothesized structural model indicates that the data fits the structural model fits with Goodness of Fit, GOF, as shown in Fig. 2. The GOF shows the CFI, IFI, and TLI sig- nificantly pass the cutoff value of $.90, \mathrm{x}^{2}(340)=657.362$, $\mathrm{GFI}=.927, \mathrm{CFI}=.964, \mathrm{IFI}=.964, \mathrm{NFI}=.928$, TLI $=.960$, and RMSEA $=.042$. The RMSEA value is .042 , which fall between the recommended range between .3 and .8 . Thus, the data fit the model. In addition, three out of four factors, namely the mastery experience, social persuasion, and physiological and affective state are found to be associated with counseling self-efficacy and predicted 19\% of the variance in counseling self-efficacy of Malaysian school counselors.

Table 3 presents the four (4) sources of counseling selfefficacy examined in this study. The mastery experience exhibits the highest positive association with counseling self-efficacy $(\beta=.411, \mathrm{p}<.001)$.

Based on the result above, we could conclude that:

a) There is a statistically significant positive relationship between mastery experience and counseling selfefficacy $(\beta=.411$, C.R. $=8.167, \mathrm{p}<.001)$.

b) There is a statistically significant positive relationship between social persuasion and counseling self-efficacy $(\beta=.112$, C.R. $=2.072, \mathrm{p}<.05)$.

c) There is no statistically significant relationship between vicarious learning and counseling self-efficacy $(\beta=-.017$, C.R. $=-.310, \mathrm{p}>.05)$.

d) There is a statistically significant negative relationship between physiological and affective state and counseling self-efficacy $(\beta=-.086$, C.R. $=-1.975, \mathrm{p}<.05)$. 


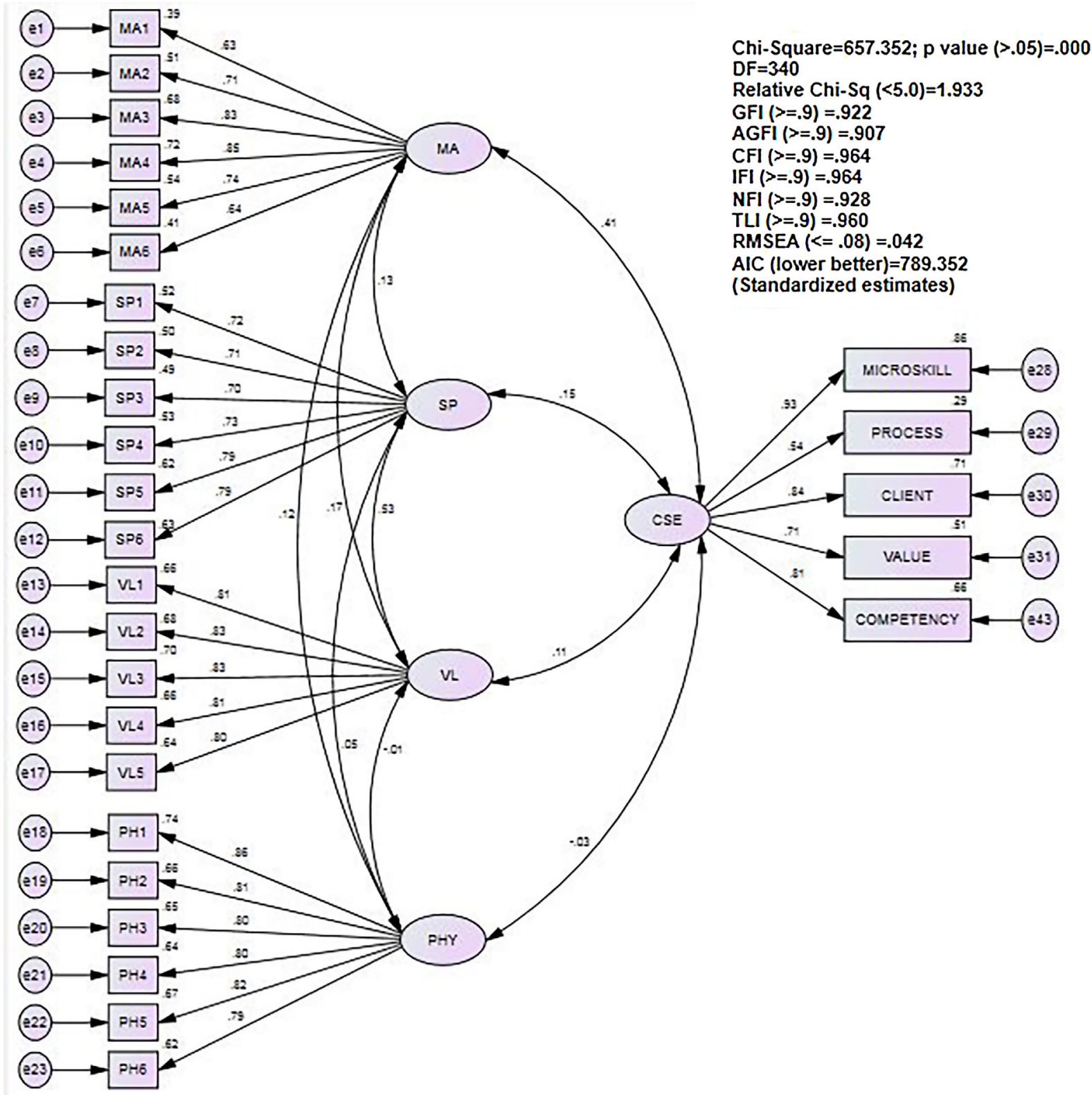

Fig. 1. The measurement model.

\section{Discussion}

This study aims to examine the relationship between the four sources of counseling self-efficacy and counseling self-efficacy. The mastery experience shows the highest association with counseling self-efficacy belief. This result is consistent with previous studies and findings, in which the mastery experience is classified as the most powerful source of information being retained and formed (Wan Jaafar et al., 2009; Zelenak, 2015). In a similar vein, Lent, Lopez, and Bieschke (1991) suggested that personal performance accomplishment and success are the strongest and most influential sources of self-efficacy among 138 students of introductory psychology. The finding is simi- lar to a study by Tang et al. (2004), which found that the individual's past work experience is associated with counseling self-efficacy. Direct positive outcomes will increase the counselors' self-efficacy beliefs while direct negative results will weaken the self-efficacy beliefs (Hutchison, Follman, Sumpter, \& Bodner, 2006). The individual's past learning experience serves as a platform to build confidence and a foundation for mastery experience (Jensen, 2012).

The verbal verdict, assessment or judgment from supervisors, peers, colleagues, school authorities, parents, and students could affect and influence the counselors' selfefficacy belief. Social acceptance and support are highly associated with self-efficacy (Booker, 2007). A collegiate, 


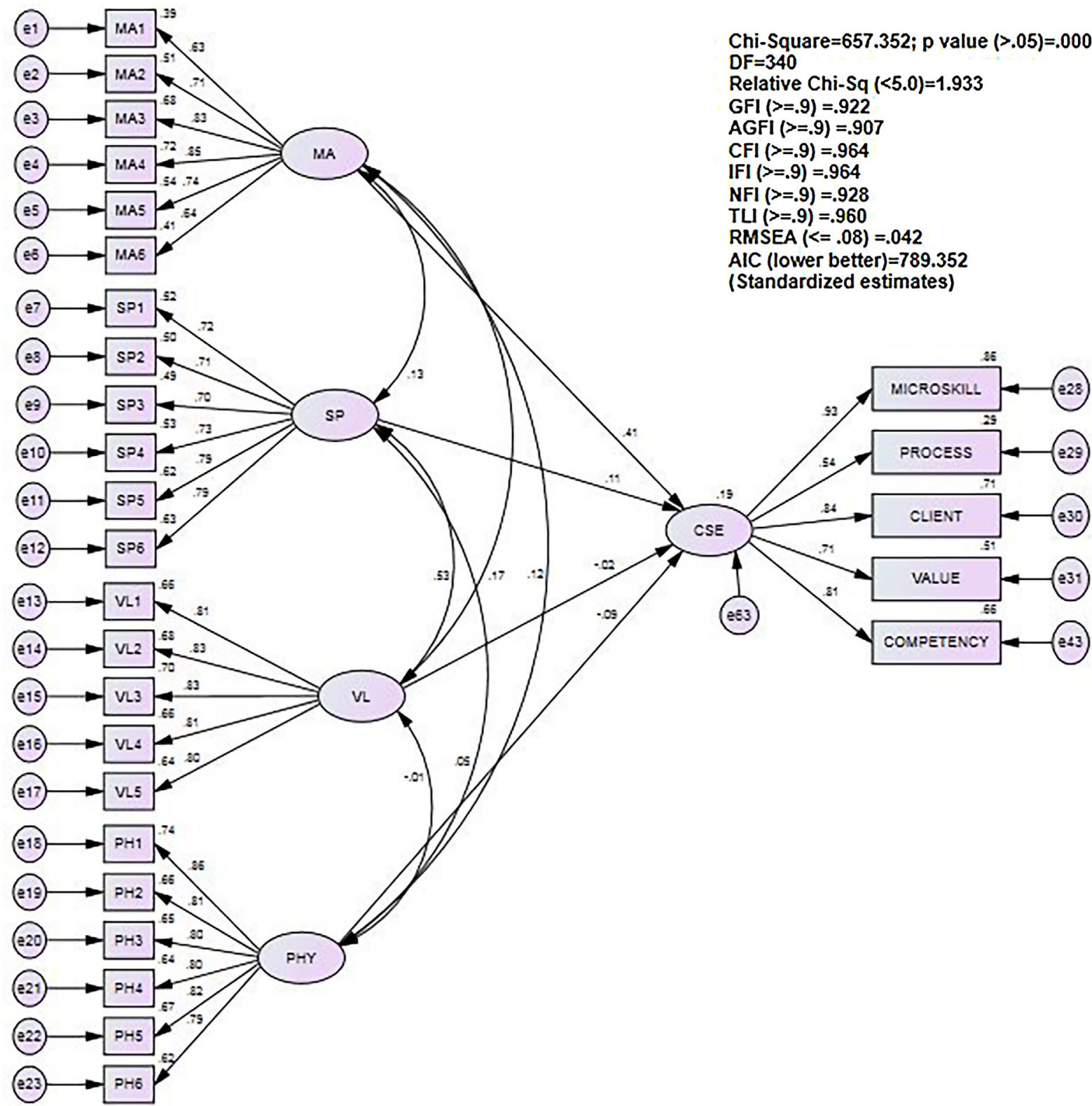

Fig. 2. The structural model.

private, and secure platform for brainstorming and the case planning allow the counselors to discuss and listen to suggestions and feedbacks while protecting the clients' interest. Assurance from peers or supervisors would strengthen the counselors' self-belief when they are doubtful in managing a case related to conceptualization, technique, or a treatment plan. For instance, a peer support is used as a method for managing the counselor education doctoral students' multiple roles (Minor, Pimpleton, Stinchfield, Stevens, \& Othman, 2013); and a peer support is found to be beneficial. Furthermore, with the technology advancement, peers support is available 24-h a day and seven-day a week through the online platform. It promotes the exchanging of ideas, seeking clarity, and questioning doubts without worrying about being judged.

The result indicates no relationship between vicarious learning and counseling self-efficacy. In the counseling field, indirect learning occurs when a supervisor demonstrates the skills, techniques, and/or approaches used in a counseling session during supervision. Feedback and criticism are part of the learning process in this relationship. Through supervision, one obtains feedbacks and learns directly from the supervisor (Lambie, 2007) with an opportunity to discuss difficulties.

A study by Ruble, Usher, and McGrew (2011) on teachers working with autistic students suggested a similar finding; a significant negative association was found between 
physiological and affective state and teachers' self-efficacy. Participants who experienced burnout and depersonalization implied a low level of self-efficacy. Emotional state affects self-efficacy (Bandura \& Adams, 1977). Mehr, Ladany, and Caskie (2014) reported that counselors' anxiety during supervision is reduced significantly if they have a high level of counseling self-efficacy. The individual is more relaxed and comfortable in sharing during supervision. Thus, it is essential for counselors to maintain and strive for a balanced self-care by developing a coping mechanism, such as exercising regularly, seeking peer or colleague support, learning to say no by setting boundaries and developing a good sense of humor (Benoit, Veach, \& LeRoy, 2007).

\section{Conclusion}

This present study contributes to the counselors' personal and professional development literature. The study further substantiates the theoretical understanding of the association between sources of self-efficacy and counseling self-efficacy in the Malaysian context. A search on journal databases does not produce many studies in this aspect among the school counselors in Malaysia. However, causation is not possible in this study as it merely looks into the variables relationship.

The methodology for data collection depends solely on self-reported measures that may encourage socially desirable responses (McKibben \& Silvia, 2015).

This study investigates how to maximize the counselors' counseling self-efficacy by manipulating the way how the four main sources of counseling self-efficacy were delivered. The responses to mastery experience, social persuasion, and physiological and affective state provided an insight of how the school counselors' sources of selfefficacy could be used to suggest focus priority to the counselor educators, when resources are limited. Increase in mastery experience or social persuasion increased the counseling self-efficacy. Between the two, mastery experience shows strongest relationship with counseling self-efficacy. Mastery experience such as workshops, training, clinical sessions, and an internship would provide direct opportunities in enhancing the counselors' mastery experience and should be considered as a tool by counselor educators. However, decrease in physiological and affective state increased the counseling self-efficacy. Thus, maintaining a calm and positive thinking is essential to influence the school counselors' state of mind.

The priority and focus among four sources may vary according to the context. However, in this study, three out of four sources of self-efficacy reported association with the counselors' counseling self-efficacy and could be used as the point of reference when counselor educators or supervisors intend to develop the counselors' sense of self-efficacy by focusing on any of the four sources of selfefficacy.

\section{References}

Al-Darmaki, F. R. (2012). Relationships between career counseling attitudes and self-esteem and self-efficacy among Emirati uni- versity students. Journal of Career Development, 39(2), 143-161. http://dx.doi.org/10.1177/0894845310380046

Argyropoulou, E. P., Sidiropoulou-Dimakakou, D., \& Besevegis, E. G. (2007). Generalized self-efficacy, coping, career indecision, and vocational choices of senior high school students in Greece: Implications for career guidance practitioners. Journal of Career Development, 33(4), 316-337. http://dx.doi.org/10.1177/0894845307300412

Bandura, A. (1986). Social foundation of thought and action-A social cognitive theory. New Jersey: Prentice-Hall, Inc.

Bandura, A. (1989). Human agency in social cognitive theory. American Psychologist, 44, 1175-1184.

Bandura, A. (1990). Perceived self-efficacy in the exercise of personal agency. Journal of Applied Sport Psychology, 2, 128-163. Reprint of Bandura, A. (1989). Perceived self-efficacy in the exercise of personal agency. The Psychologist: Bulletin of the British Psychological Society, 2, 411-424.

Bandura, A. (1997). Self-efficacy: The exercise of control. New York: Freeman.

Bandura, A., \& Adams, N. (1977). Analysis of self-efficacy theory of behavior change. Cognitive Therapy E' Research, 1(4), 287-310.

Benoit, L. G., Veach, P. M., \& LeRoy, B. S. (2007). When you care enough to do your very best: Genetic counselor experiences of compassion fatigue. Journal of Genetic Counseling, 16(3), 299-312. http://dx.doi.org/10.1007/s10897-006-9072-1

Bong, M., \& Skaalvik, E. M. (2003). Academic self-concept and self-efficacy: How different are they really? Educational Psychology Review, 15, 1-4.

Booker, K. C. (2007). Likeness, comfort, and tolerance: Examining African American adolescents' sense of school belonging. Urban Review, 39(3), 301-317. http://dx.doi.org/10.1007/s11256-007-0053-y

Britner, S. L., \& Pajares, F. (2006). Sources of science self-efficacy beliefs of middle school students. Journal of Research in Science Teaching, 43(5), 485-499. http://dx.doi.org/10.1002/tea.20131

Can, G. (2010). Development of the elementary school counselor selfefficacy scale. Procedia Social and Behavioral Sciences, 9, 1158-1161.

Easton, C., Martin, W. E., Jr., \& Wilson, S. (2008). Emotional intelligence and implications for counseling self-efficacy: Phase II. Counselor Education and Supervision, 47(4), 218-232.

Fan, J., Litchfield, R. C., Islam, S., Weiner, B., Alexander, M., Liu, C., et al. (2013). Workplace social self-efficacy: Concept, measure and initial validity evidence. Journal of Career Assessment, 21(1), 91-110.

Fenollar, P., Roman, S., \& Cuestas, P. J. (2007). University students' achievement performance: An integrative conceptual framework and empirical analysis. British Journal of Educational Psychology, 77, 873-891.

Fort, I., Jacquet, F., \& Leroy, N. (2011). Self-efficacy, goals, and job search behaviors. Career Development International, 16(5), 469-481. http://dx.doi.org/10.1108/13620431111168886

Hair, J., Black, W. C., Babin, B. J., \& Anderson, R. E. (2010). Multivariate data (7th ed.). Upper Saddle River, New Jersey: Pearson Education International.

Hair, J. F., Black, W. C., Babin, B. J., Anderson, R. E., \& Tatham, R. L. (2006). Multivariate data analysis. Upper Saddle River, NJ: Prentice-Hall.

Hanson, M. G. (2006). Counselor self-efficacy: Supervision contributions, impact on performance, and mediation of the relationship between supervision and performance. Southern Illinois University. Available from ProQuest Dissertations and Theses database. (UMI No. 3229884). http://libres.uncg.edu/ir/uncg/listing.aspx?id=1865http://ir.library.oregonstate edu/xmlui/handle/1957/44184. (Retrieved 29 May 2013)

Havens, M. C. (2003). Mental health counselor's self-efficacy and the relationship to multicultural counseling competency.. http://ir.library.oregonstate.edu/xmlui/handle/1957/11158. (Retrieved 3 June 2015)

Hutchison, M. A., Follman, D. K., Sumpter, M., \& Bodner, G. M. (2006). Factors influencing the self-efficacy beliefs of first-year engineering students. Journal of Engineering Education, 95(1), 39-47. http://dx.doi.org/10.1002/j.2168-9830.2006.tb00876.x

Iannelli, R. J. (2000). A Structural Equation Modeling examination of the relationship between counseling self-efficacy, counseling outcome expectations, and counselor performance (Doctoral Dissertation). University Missouri-Kansas City

Jensen, R. E. (2012). Sex educators and self-efficacy: Toward a taxonomy of enactive mastery experiences. Health Education \& Behavior, 39(3), 259-267. http://dx.doi.org/10.1177/1090198111399756

Klassen, R. M., \& Chiu, M. M. (2010). Effects on teachers' selfefficacy and job satisfaction: Teacher gender, years of experience, and job stress. Journal of Educational Psychology, 102(3), 741-756. http://dx.doi.org/10.1037/a0019237 
Lahuis, D. M. (2005). Individual differences in applicant reactions: A jobsearch perspective. International Journal of Selection and assessment 13(2), 150-159.

Lambie, G. W. (2007). The contribution of ego development level to burnout in school counselors: Implications for professional school counseling. Journal of Counseling \& Development, 85, 82-88.

Larson, L. M., \& Daniels, J. A. (1998). Review of the counseling self-efficacy literature. The Counseling Psychologist, 26(2), 179-218. http://dx.doi.org/10.1177/0011000098262001

Larson, L. M., Suzuki, L. A., Gillespie, K. N., Potenza, M. T., Bechtel, M. A., \& Toulouse, A. L. (1992). Development and validation of the counselling self-estimate inventory. Journal of Counseling Psychology, 39(I), 105-120.

Lent, R., Lopez, F., \& Bieschke, K. (1991). Mathematics self-efficacy: Sources and relation to science-based career choice. Journal of Vocational Behavior, 49, 292-308.

McKibben, W. B., \& Silvia, P. J. (2015). Evaluating the distorting effects of inattentive responding and social desirability on self-report scales in creativity and the arts. The Journal of Creative Behavior http://dx.doi.org/10.1002/jocb.86

Mehr, K. E., Ladany, N., \& Caskie, G. I. L. (2014). Factors influencing trainee willingness to disclose in supervision. Training and Education in Professional Psychology, 9(1), 44-51. http://dx.doi.org/10.1037/tep0000028

Minor, A. J., Pimpleton, A., Stinchfield, T., Stevens, H., \& Othman, N. A (2013). Peer support in negotiating multiple relationships within supervision among counselor education doctoral students. International Journal for the Advancement of Counselling, 35(1), 33-45. http://dx.doi.org/10.1007/s10447-012-9161-9

Nunnally, J., \& Bernstein, I. (1994). Psychometric theory (3rd ed.). New York: McGraw-Hill.

Ooi, P. B., Wan Marzuki, W. J., \& Baba, M. (2016). Differences in counselors career outputs in view of licensure status in Malaysia. International Journal of Social Sciences E' Humanity, 6(4), 251-255.

Palmer, D. (2011). Sources of efficacy information in an in-service program for elementary teachers. Science Education, 95(4), 577-600. http://dx.doi.org/10.1002/sce.20434

Rigotti, T., Schyns, B., \& Mohr, G. (2008). A short version of the occupational self-efficacy scale: Structural and construct validity across five countries. Journal of Career Assessment, 16(2), 238-255.

Ruble, L. A., Usher, E. L., \& McGrew, J. H. (2011). Preliminary investigation of the sources of self-efficacy among teachers of students with autism. Focus on Autism and Other Developmental Disabilities, 26(2), 67-74. http://dx.doi.org/10.1177/1088357610397345
Sawyer, C., Peters, M. L., \& Willis, J. (2013). Self-efficacy of beginning counselors to counsel clients in crisis. The Journal for Counselor Preparation and Supervision, 5(2).

Schiele, B. E. (2013). The importance of counseling self-efficacy in school mental health (Master's Thesis). http://scholarcommons.sc.edu/etd/2548. (Retrieved 2 July 2014)

Schiele, B. F., Weist, M. D., Youngstrom, E. A., Stephen, S. H., \& Lever, N. A. (2014). Counseling self-efficacy, quality of services and knowledge of evidence-based practices in school mental health. The Professional Counselor, 4(5), 467-480.

See, C. M., \& Ng, K. M. (2010). Counseling in Malaysia: History, current status:and future trends. Journal of Counseling and Development, 88, $18-22$.

Sharply, C., \& Ridgway, I. (1993). An evaluation of the effectiveness of self-efficacy as a predictor of trainees' counseling skills performance. British Journal of Guidance and Counseling, 21, 73-81.

Stajkovic, A. D., \& Sommer, S. M. (2000). Self-efficacy and causal contributions: Direct and reciprocal links. Journal of Applied Social Psychology, 30, 707-737.

Tabachick, B. G., \& Fidell, L. S. (2007). Using multivariate statistics (5th ed.) Boston: Pearson Education Inc.

Tang, M., Addison, K. D., Norman, R., Connell, W. O., \& Stewart-Sicking, J. A. (2004). Factors that influence self-efficacy of counseling students: An exploratory study self-efficacy. Counselor Education $\mathcal{E}$ Supervision, 44, 70-81. http://dx.doi.org/10.1002/j.1556-6978.2004.tb01861.x

Usher, E. L., \& Pajares, F. (2009). Sources of self-efficacy in mathematics: A validation study. Contemporary Educational Psychology, 34, 89-101.

Wan Jaafar, W. M., Mohamed, O., Bakar, A. B., \& Ahmad Tarmizi, R. (2009) The influence of counseling self-efficacy towards trainee counselor performance. International Journal of Learning, 16(8), 247-260.

Warren, J. S., \& Salazar, B. C. (2014). Youth self-efficacy domains as predictors of change in routine community mental health services. Psychotherapy Research, 1-12 http://dx.doi.org/10.1080/10503307.2014.932464

Wilde, M. O., Park, D., \& Lee, C. C. (2013). Training transformed school counselors. In C. S. Clauss-Ehlers, Z. N. Serpell, \& M. D. Weist (Eds.), Handbook of culturally responsive school mental health: advancing research, training, practice, and policy (pp. 189-196). New York: Springer. http://dx.doi.org/10.1007/978-1-4614-4948-5_14

Zelenak, M. S. (2015). Measuring the sources of self-efficacy among secondary school music students. Journal of Research in Music Education 62(4), 389-404. http://dx.doi.org/10.1177/0022429414555018

Zimmerman, B. J., \& Bandura, A. (1994). Impact of self-regulation influence on writing course attainment. American Educational Research Journal, $31,845-862$. 